\title{
Fatty Acid 21:5
}

National Cancer Institute

\section{Source}

National Cancer Institute. Fatty Acid 21:5. NCI Thesaurus. Code C68365.

A polyunsaturated long-chain fatty acid with a 21-carbon backbone and 5 double bonds.

The 21:5 class of fatty acids is rarely found in nature. 